\title{
PREFERÊNCIA DE Cornitermes cumulans (Kollar, 1832) (ISOPTERA: TERMITIDAE) A DIFERENTES ESTRUTURAS MORFOLÓGICAS DE Brachiaria brizantha EM PASTAGENS DEGRADADAS NA AMAZÔNIA
}

\author{
Patrícia da Silva Leitão-Lima ${ }^{1}$; Eduardo do Valle Lima ${ }^{1}$; Darley Oliveira Cutrim ${ }^{1}$; Daniel Pereira \\ Pinheiro ${ }^{1}$ \\ ${ }^{1}$ Universidade Federal Rural da Amazônia - UFRA, Campus de Parauapebas (UFRA/Carajás), Centro Universitário de \\ Parauapebas - CEUP, s/nº, Quadra Especial, CEP: 68515-000, Parauapebas - PA. E-mail: eduardo.valle_lima@yahoo.com.br
}

\section{RESUMO}

O objetivo do trabalho foi avaliar a preferência de Cornitermes cumulans a diferentes estruturas morfológicas de Brachiaria brizantha, "in natura" e secas, colhidas de pastagens, comparadas à preferência por isca de papelão utilizada em sistemas de monitoramento. Quatro experimentos foram realizados na UFRA/Carajás, em Parauapebas-PA, em outubro, novembro e dezembro de 2005 e fevereiro de 2006. Foram preparados ninhos artificiais com fragmentos de colônias (arenas), coletadas em três propriedades, contendo 300 operários, 50 ninfas e 50 soldados, mantidos em recipientes plásticos, com furos para o encaixe de tubos de vidro, preenchidos com $7 \mathrm{~cm}^{3}$ de cada tratamento. O delineamento experimental foi o de blocos ao acaso, com 7 tratamentos (folha, colmo e raiz, secos ou "in natura", e isca de papelão), e 8 repetições. As arenas foram colocadas em bancadas, sendo monitorados as temperaturas máxima e mínima, e a visitação dos cupins. Foi considerado preferido o material mais consumido, sendo que o término de cada experimento foi definido no momento em que se observou a morte de todos os indivíduos ou quando o conteúdo de um tratamento foi completamente consumido. Os tratamentos "in natura" foram os preferidos, onde se destacou o colmo seguido da folha. Quanto ao papelão, não se mostrou atrativo para o consumo de C. cumulans, o que sugere que este não seja efetivo para o monitoramento no campo.

Palavras-chave: braquiária, cupim, hábitos alimentares, monitoramento, pragas de pastagens

\section{PREFERENCE OF Cornitermes cumulans (Kollar, 1832) (ISOPTERA: TERMITIDAE): TO DIFFERENT MORPHOLOGICAL STRUCTURES OF Brachiaria brizantha FROM DEGRADED PASTURES IN THE AMAZON REGION}

\section{ABSTRACT}

The objective of this study was to evaluate the preference of Cornitermes cumulans for different morphological structures of Brachiaria brizantha (leaves, stalks, and roots), either fresh or dry, from pastures, as compared to preference for cardboard baits used in monitoring systems. Four experiments were conducted in Laboratório de Zootecnia (animal husbandry laboratory), at UFRA/Carajás in Parauapebas-PA, Brazil. Artificial nests were prepared in the laboratory during the months of October, November, and December 2005, and February 2006, using fragments of colonies collected from three farm properties, containing 300 workers, 50 nymphs, and 50 soldiers, maintained in plastic pots with holes to fit glass vials filled with $7 \mathrm{~mL}$ of each treatment. A random block experimental design was adopted, with 7 treatments (leaves, stalks, and roots, either fresh or dry, and corrugated cardboard baits) and 8 replicates. The most consumed material 


\section{Preferência de Cornitermes cumulans (Kollar, 1832) (Isoptera: Termitidae) a diferentes estruturas morfológicas de Brachiaria brizantha em pastagens degradadas na Amazônia}

was considered the preferred treatment. The end of each experiment was defined as the time when all individuals were dead or when the content of a treatment was completely consumed. Fresh treatments were preferred, considering consumption and visits; stalks, followed by leaves were the most important substrates. The cardboard was not very attractive for consumption, suggesting that it is ineffective to monitoring the incidence of $C$. cumulans in the field.

Key words: brachiaria, feeding habits, monitoring, pasture pests, termite

\section{INTRODUÇÃO}

Os cupins do gênero Cornitermes são insetos sociais que vivem em ninhos numa porção visível no solo, os cupinzeiros (Embrapa, 1996). A colônia é dividida em castas, sendo os operários o maior grupo, com a finalidade de desenvolver todas as funções de manutenção, inclusive a coleta de material vegetal, denominado de forrageamento, que se traduz na busca do alimento e outros materiais. Os cupins podem ocupar extensas áreas de pastagens, com numerosos ninhos, sendo considerados praga que potencialmente diminui a área útil das pastagens. Citado como praga em canade-açúcar, milho, arroz, café, amendoim e eucalipto (Cancello, 1989), o cupim é praga secundária em pastagens, não causando aparente prejuízo à produção de forragem em pastagens cultivadas (Valério, 2001). Valério (1995), no Mato Grosso do Sul, verificou que um cupinzeiro ocupava uma área média de $0,5 \mathrm{~m}^{2}$. Czepak et al. (2003), em uma pastagem degradada em Goiás, quantificaram uma densidade de 73 cupinzeiros $\mathrm{ha}^{-1}$, correspondendo a $0,4 \%$ da área de pastagem. Coenza \& Carvalho (1974), não constataram redução na produção e na cobertura vegetal dos pastos com até 160 cupinzeiros ha ${ }^{-1}$. Portanto, os cupinzeiros não reduzem substancialmente a área útil dos pastos (Valério et al., 1982). Todavia, o elevado número de cupinzeiros limitaria a movimentação de máquinas, implementos e animais, causando dificuldades nos tratos culturais. Além disso, é também conhecida a capacidade dos cupinzeiros de abrigarem cobras, aranhas, escorpiões, vespas, abelhas e ratos, além da imagem de abandono, que tem sido associada a pastagens degradadas (Valério et al., 1998).

Há escassez de pesquisas no Brasil sobre a preferência de Cornitermes cumulans, cujo questionamento é se forrageiam ou não tecidos vivos, pois, segundo Silveira Neto (1976), este inseto pode danificar os sistemas radiculares vivos. Em contrapartida, Macedo (1995) afirmou que os cupins alimentam-se de material vegetal morto, e que forrageiam através de galerias subterrâneas, sendo raro o ataque a tecidos vivos. Em laboratório, Nogueira (1981) observou que os operários coletaram mais capim morto do que vivo, e quando oferecidas raízes e folhas mortas, preferiram as últimas. Segundo Berti Filho (1993) $C$. cumulans prefere basicamente material vegetal morto como alimento ou material para a estruturação do ninho, sendo raro o consumo de tecidos vivos da planta

Portanto, surge o questionamento se em pastagens degradadas ou em processo de degradação ocorre a preferência de Cornitermes cumulans por tecido vegetal vivo ou morto. Assim, objetivou-se avaliar a preferência de $C$. cumulans a diferentes estruturas de $B$. brizantha (folha, colmo e raiz), "in natura" e secas, de pastagens degradadas na Amazônia comparadas a iscas de papelão.

\section{MATERIAL E MÉTODOS}

O trabalho foi realizado no período de agosto de 2005 a fevereiro de 2006, 
coletando-se os cupinzeiros utilizados no experimento na Área de Proteção Ambiental do Igarapé Gelado (APA do Igarapé Gelado) $\left(6^{\circ} 00^{\prime}, \mathrm{S}\right.$ e $\left.49^{\circ} 57^{\prime} \mathrm{O}\right)$, localizada no município de Parauapebas, região sudeste do Estado do Pará.

A classificação da área quanto à vegetação é a Floresta Equatorial Perúmida (Floresta Amazônica) (IBGE, 2006). A média de chuva na APA do Igarapé Gelado está em torno de 1.700 a $2.000 \mathrm{~mm}^{\mathrm{ano}}{ }^{-1}$, a qual se concentra entre novembro a abril (70\%). As temperaturas médias anuais são elevadas, sendo em geral maiores que $23^{\circ} \mathrm{C}$, umidade relativa de aproximadamente $70 \%$ nos meses mais secos. Possui um relevo predominantemente plano a suave ondulado (até 8\%). Apresenta um mosaico de solos formados em sua grande extensão por Argissolos de textura argilosa, onde a maior parte classifica-se como Argissolo vermelhoamarelo, que são em geral ácidos de baixa fertilidade, formados por argilas de baixa atividade, com saturação de Al maior que $50 \%$ e saturação de bases menor que $50 \%$, segundo os critérios descritos no Sistema Brasileiro de Classificação de Solos (Campo, 1999; Embrapa, 2006).

$\mathrm{Na}$ APA do Igarapé gelado foram selecionadas três propriedades rurais (lotes de no máximo 75 ha), denominadas atualmente de Sítio Bom Sossego, Sítio Dois Irmãos e Sítio Xavier. Os três lotes apresentavam cultivo de pastagem com Brachiaria brizantha cv. Marandu, estabelecidas há mais de 15 anos após o corte e queima da floresta primária, com evidências nítidas de degradação, com grande número de cupinzeiros de montículo, intenso ataque de cigarrinha-das-pastagens e alta infestação de plantas daninhas, que diminuíam a população de $B$. brizantha, com redução na oferta de forragem e, consequentemente, a capacidade de suporte animal.

Em cada propriedade foi escolhido um piquete para a coleta dos cupinzeiros. Cada piquete selecionado foi georeferenciado com a utilização de um aparelho GPS, onde se determinou o perímetro e área total das propriedades.

Foram coletadas 15 amostras simples de solo de cada piquete, a uma profundidade de 0 a $20 \mathrm{~cm}$, com o auxílio de enxadeco e pá de corte, formando-se amostras compostas, sendo retirada uma única amostra representativa de cada área, para a análise de fertilidade (Tabela 1).

Tabela 1. Atributos químicos do solo $(0-20 \mathrm{~cm})$ antes das coletas de cupins para implantação dos experimentos. Propriedades Sítio Dois Irmãos, Sítio Xavier e Sítio Bom Sossego. Parauapebas-PA, 2005.

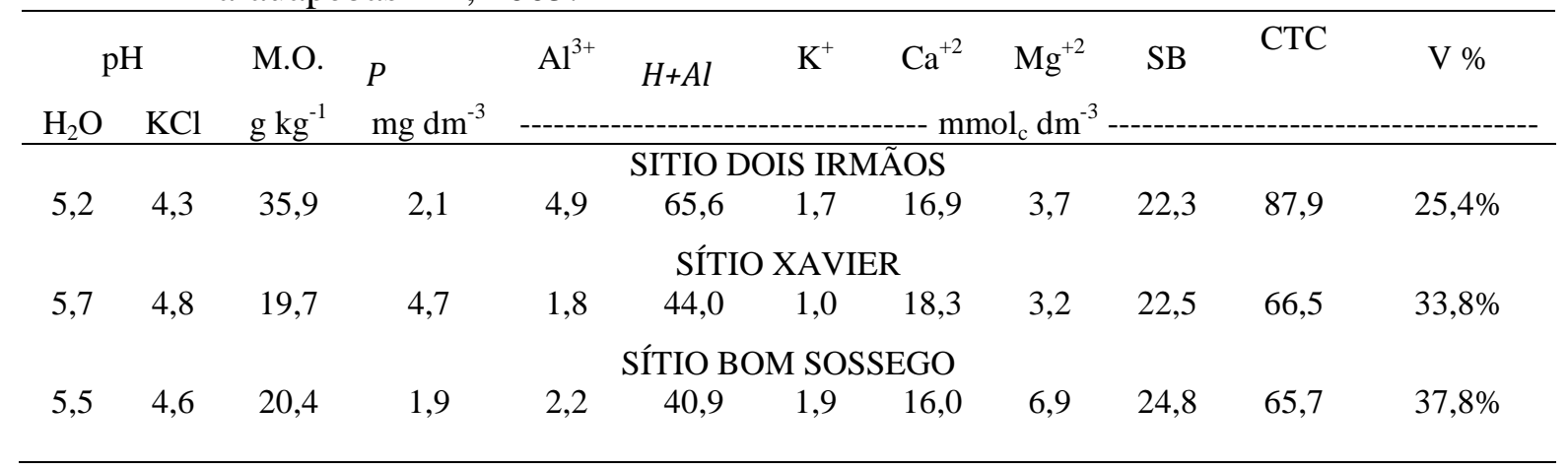




\section{Preferência de Cornitermes cumulans (Kollar, 1832) (Isoptera: Termitidae) a diferentes estruturas morfológicas de Brachiaria brizantha em pastagens degradadas na Amazônia}

Posteriormente, foi efetuada a contagem do número total de cupinzeiros por unidade de área, facilitando no momento das coletas a identificação da espécie trabalhada e se o ninho estava ativo ou não. A densidade de cupinzeiros ativos foi de 65,47 e 65 cupinzeiros ha ${ }^{-1}$ nos sítios Bom Sossego, Sítio Dois Irmãos e Sítio Xavier, respectivamente.

Para cada teste de preferência, nos meses de outubro, novembro e dezembro de 2005 e fevereiro de 2006 (4 experimentos), coletou-se aleatoriamente, oito cupinzeiros ativos de $C$. cumulans, nas áreas de pastagens das propriedades rurais selecionadas, por meio da escavação manual e tombamento dos mesmos.

Os cupinzeiros coletados foram encaminhados ao Laboratório Multidisciplinar do Centro Universitário de Parauapebas - CEUP, para a implantação dos experimentos.

A escolha da proporção de cupins para os testes de preferência foi baseada em estudos realizados por Almeida (1994) com Heterotermes tenuis em laboratório, onde o referido autor utilizou operários e soldados na proporção de 5:1.

Procurando simular as mesmas condições de uma colônia no campo, decidiu-se pela inclusão de ninfas neste experimento, semelhante ao utilizado por Leitão-Lima (2005). Portanto, para os experimentos de preferência, em laboratório, utilizou-se em cada unidade experimental, 300 operários, 50 soldados e 50 ninfas (6:1:1), retirados de um mesmo ninho.

Os cupins coletados e separados na proporção preestabelecida foram acondicionados em recipientes plásticos transparentes com tampa escura, de $26 \mathrm{~cm}$ de diâmetro e $12 \mathrm{~cm}$ de altura, contendo fragmentos de cupinzeiro e gesso na base interior para a manutenção da umidade. Os recipientes continham sete furos para $o$ encaixe de tubos de vidro de $2 \mathrm{~cm}$ de diâmetro e $8 \mathrm{~cm}$ de comprimento, onde no interior de cada um foi aplicado os tratamentos referentes ao teste de preferência. Ressalta-se que no interior dos recipientes, também foi colocado um recipiente plástico de $9,5 \mathrm{~cm}$ de diâmetro e 5 $\mathrm{cm}$ de altura, de coloração vermelha transparente, com a abertura invertida para baixo, contendo no seu interior um pouco do fragmento do cupinzeiro com várias aberturas laterais, permitindo o trânsito livre dos cupins. O conjunto total deste sistema formado foi denominado de "arena para teste de preferência". No interior de cada tubo de vidro, com o auxílio de uma proveta de 10 $\mathrm{cm}^{3}$, foram adicionados um volume de $7 \mathrm{~cm}^{3}$ de diferentes materiais testados. Esta padronização no volume conhecido $\left(7 \mathrm{~cm}^{3}\right)$, foi necessária, pois a quantidade a ser oferecida aos cupins poderiam variar em função das diferentes composições e texturas dos materiais, além de dificultar a avaliação de preferência, pois se teria que trabalhar com recipientes de tamanhos diferentes (Figura 1).

Nos meses de outubro, novembro e dezembro de 2005 e fevereiro de 2006, quatro experimentos, foram realizados com os seguintes materiais: isca de papelão ondulado cortado em pedaços de $0,5 \mathrm{~cm} \mathrm{x}$ $0,5 \mathrm{~cm}$ e diferentes estruturas morfológicas de $B$. brizantha (folha seca e "in natura", colmo seco e "in natura", raiz seca e "in natura"), coletadas dos piquetes préselecionados.

A escolha do papelão ondulado, deveu-se ao fato de sua utilização como isca artificial no monitoramento da infestação de Heterotermes em canaviais (Almeida \& Alves, 1995). Deste modo, este material foi testado como isca para C. cumulans. 


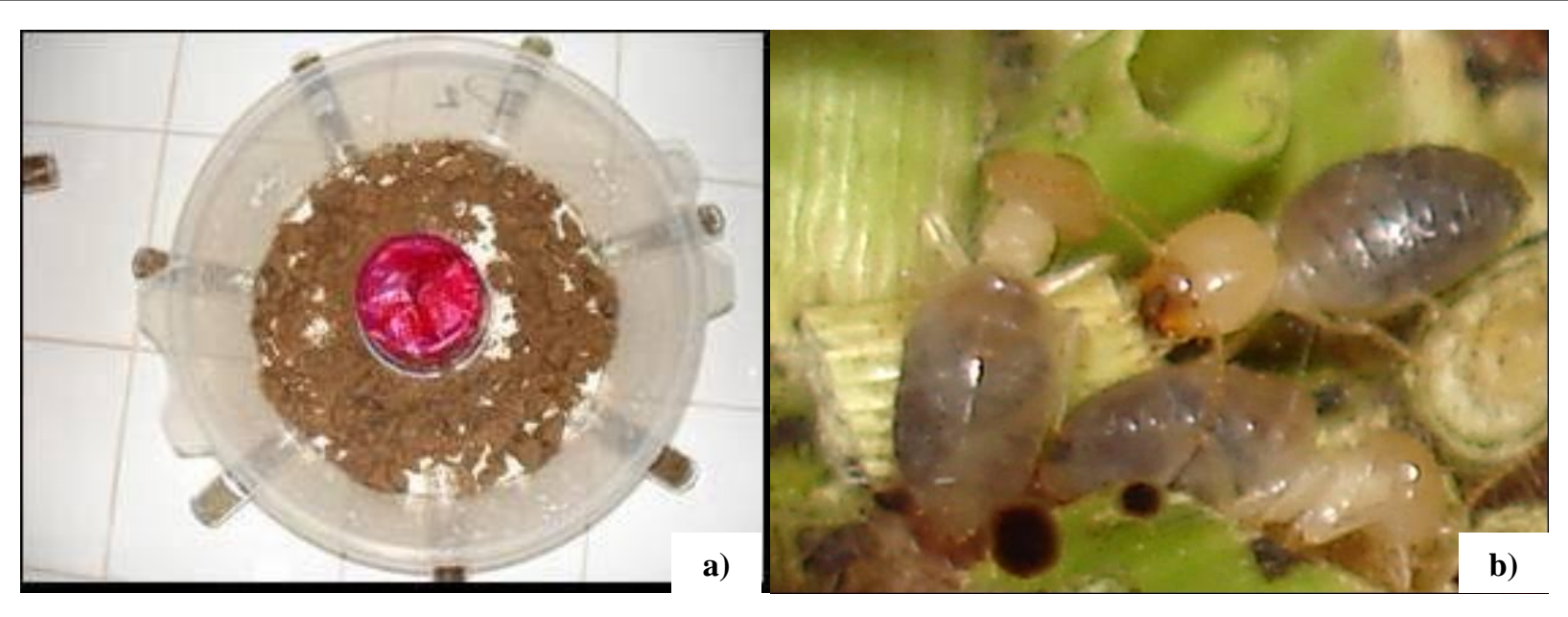

Figura 1. Sistema utilizado para manutenção de $C$. cumulans em condição artificial no laboratório: a) arena para teste de preferência e b) operários no interior do tubo de vidro do tratamento colmo "in natura". Parauapebas-PA, 2005.

Para os tratamentos com material seco (folha, colmo e raiz), uma semana antes da montagem de cada experimento de preferência, coletou-se aleatoriamente nos piquetes pré-selecionados, plantas inteiras de $B$. brizantha. No laboratório, estas foram lavadas em água corrente, seguida de enxágue com água destilada, para retirada de resíduos e partículas de solo, principalmente das raízes. Posteriormente, com auxílio de tesoura, as plantas foram separadas por estruturas morfológicas e colocadas em sacos de papel para secagem em estufa de circulação forçada de ar a temperatura de $105^{\circ} \mathrm{C}$, por um período de 72 horas, até peso constante.

As coletas, no campo, das plantas para os três tratamentos "in natura", foram realizadas na mesma data da retirada dos cupinzeiros. O procedimento de retirada de impurezas e separação das estruturas morfológicas foi o mesmo efetuado para os materiais secos, sendo que após a lavagem houve a secagem em papel toalha, retirandose o excesso de umidade, para que os tratamentos "in natura", também pudessem ser cortados em tamanhos de $0,5 \mathrm{~cm}$ de comprimento, e imediatamente oferecidos aos cupins.
O delineamento experimental utilizado foi em blocos ao acaso, com sete tratamentos (folha, colmo e raiz, secos e "in natura", e isca de papelão ondulado) e oito repetições. Ressalta-se que cada bloco era constituído por uma arena, onde se encontravam encaixados os sete tubos de vidro contendo os referidos tratamentos (Figura 1). Para manter a umidade, no interior das arenas, além do gesso na base, esta foi umedecida diariamente com água destilada.

As arenas foram colocadas nas bancadas do laboratório, com a temperatura monitorada diariamente, com auxílio de um termômetro conjugado de máxima e mínima, além disso, foi avaliada a visitação dos cupins e as observações de preferência de $C$. cumulans em todos os tratamentos. Foi considerado "preferido" o material forrageado ou retirado do interior dos tubos de vidro. O experimento finalizava, a cada mês, no momento em que se observava a morte de todos os indivíduos no interior dos recipientes ou na retirada total do material contido nos tubos de vidro. Ao término de cada experimento foi determinado o volume dos resíduos mantidos nos tubos.

Os resultados obtidos nos testes de preferência para os quatro experimentos, 
assim como a análise conjunta dos mesmos, foram submetidos à análise de variância, sendo as médias dos tratamentos comparadas pelo teste de Tukey $(\mathrm{P}<0,05)$. Todos os cálculos foram realizados por meio do programa de computador ESTAT (Banzato \& Kronka, 1989).

\section{RESULTADOS E DISCUSSÃO}

Na Tabela 2, observa-se que em todos os experimentos, os tratamentos "in natura" foram os preferidos pelos cupins, independentemente de qual estrutura morfológica de $B$. brizantha estava envolvida. Dentre os materiais "in natura", o colmo foi o material preferido pelos cupins, apresentando a maior redução no volume oferecido, seguidos pelos tratamentos folha e raiz "in natura". A preferência dos cupins pelo papelão ondulado apresentou um comportamento intermediário entre as estruturas morfológicas "in natura" e secas. Entre os tratamentos com materiais secos a retirada de colmos foi semelhante aos tratamentos folha e raiz seca.

A retirada dos materiais vegetais dos tubos não significa necessariamente que foram utilizados para alimentação dos cupins, pois a redução no volume dos materiais "in natura" pode ter sido destinado à estruturação do ninho. Em um estudo realizado por Fernandes \& Alves (1992) foi observado que os operários de cupins cortavam as folhas secas em partículas pequenas e misturavam com solo nas galerias da própria arena.

Para os testes de visitação realizados no laboratório, o tempo de duração para os experimentos 1 e 2 foi de 22 dias. Nos experimentos 3 e 4 a duração foi de 28 dias. É importante ressaltar que até o $14^{\circ}$ dia foi quando ocorreu a maior atividade de visitação dos tubos pelos cupins.

No experimento 1, os tubos contendo raiz "in natura" apresentaram a maior concentração de cupins no interior (Figura 2), com maior ocorrência durante o $6^{\circ}$ dia, mesmo não sendo o material preferido em relação aos outros tratamentos "in natura" (Tabela 2). Os tubos contendo os materiais secos apresentaram a menor frequência de visitação (Figura 2).

Tabela 2. Estruturas morfológicas residuais de B. brizantha, "in natura" e seca, e papelão ondulado, contidas nos tubos de vidro no final dos experimentos. Parauapebas-PA, $2005 / 2006$.

\begin{tabular}{|c|c|c|c|c|c|}
\hline Tratamentos & $\begin{array}{c}\text { Experimento } 1 \\
\text { (Out) }\end{array}$ & $\begin{array}{c}\text { Experimento } 2 \\
(\mathrm{Nov})\end{array}$ & $\begin{array}{l}\text { Testes de Preferência } \\
\text { Experimento } 3 \\
\text { (Dez) }\end{array}$ & $\begin{array}{c}\text { Experimento } 4 \\
(\mathrm{Fev})\end{array}$ & Média \\
\hline & $-\cdots$ & 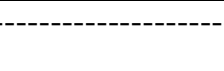 & $\mathrm{cm}^{3}$ & ----- & ---------- \\
\hline Folha "in natura" & $5,54 \mathrm{~cd}$ & $4,04 \mathrm{c}$ & $5,52 \mathrm{bc}$ & $4,62 \mathrm{~b}$ & $4,93 \mathrm{~d}$ \\
\hline Colmo "in natura" & $4,79 \mathrm{~d}$ & $4,15 \mathrm{c}$ & $5,13 \mathrm{c}$ & $2,90 \mathrm{c}$ & $4,24 \mathrm{e}$ \\
\hline Raiz "in natura" & $5,75 \mathrm{bc}$ & $6,02 \mathrm{ab}$ & $6,12 a b c$ & $6,50 \mathrm{a}$ & $6,10 \mathrm{c}$ \\
\hline Papelão ondulado & $6,54 \mathrm{ab}$ & $5,66 \mathrm{ab}$ & $6,48 \mathrm{ab}$ & $6,10 \mathrm{a}$ & $6,20 \mathrm{bc}$ \\
\hline Folha seca & $6,97 \mathrm{a}$ & $5,34 \mathrm{~b}$ & $6,70 \mathrm{a}$ & $6,12 \mathrm{a}$ & $6,28 \mathrm{bc}$ \\
\hline Colmo seco & $7,00 \mathrm{a}$ & $6,45 \mathrm{a}$ & $6,89 \mathrm{a}$ & $6,30 \mathrm{a}$ & $6,66 \mathrm{ab}$ \\
\hline Raiz seca & $7,00 \mathrm{a}$ & $6,45 \mathrm{a}$ & $6,66 \mathrm{a}$ & $6,87 \mathrm{a}$ & $6,75 \mathrm{a}$ \\
\hline Valor de F & $16,83 * *$ & $27,12 * *$ & $7,35 * *$ & $25,87 * *$ & $75,86 * *$ \\
\hline $\mathrm{CV}(\%)$ & 9,72 & 10,06 & 11,00 & 13,78 & 5,35 \\
\hline
\end{tabular}

Médias seguidas por letras iguais na coluna não diferem entre si pelo teste de Tukey a 5\%. ** significativo a 1\% pelo teste F. 
Observando-se o número de visitações diárias dos operários em relação aos registros de temperaturas máxima $\left(21\right.$ a $31^{\circ}$ C) e mínima $\left(20\right.$ a $\left.26^{\circ} \mathrm{C}\right)$, diariamente aferidas no laboratório, pode ser constatado que houve diminuição na frequência de cupins no interior dos tubos, principalmente nos $11^{\circ}, 12^{\circ}$ e $13^{\circ}$ dia, onde as temperaturas foram mais elevadas (Figura 2). Justifica-se, assim, o fato dos tratamentos úmidos (in natura) terem sido os mais consumidos no experimento (Tabela 2). Segundo Becker (1969) a temperatura ideal no laboratório para a manutenção de cupins pode variar de 20 a $28^{\circ} \mathrm{C}$, com temperatura ótima de $26^{\circ} \mathrm{C}$.

A temperatura no experimento 2 (Figura 3), atingiu o valor máximo de $32{ }^{\circ} \mathrm{C}$, acima da temperatura ótima. Nesta condição, de modo geral, as maiores visitações ocorreram até o $14^{\circ}$ dia, quando se observou diminuição das atividades dos cupins dentro das arenas. Durante todo o experimento 2 os tratamentos que apresentaram maior frequência de visitação pelos cupins foram o papelão ondulado e raiz seca, seguidos de colmo, folha e raiz "in natura", principalmente nos dias mais quentes.

No experimento 3, registraram-se os valores mais elevados de temperatura máxima, que variou de 28 a $33^{\circ} \mathrm{C}$ (Figura 4). Entre o $16^{\circ}$ ao $22^{\circ}$ dias não houve uma única visitação dos cupins aos tubos contendo os tratamentos, em decorrência das temperaturas mais elevadas ocorridas durante esse período. Durante todo o experimento os tratamentos mais visitados foram colmo, raiz e folha "in natura", confirmando o mesmo comportamento dos experimentos efetuados anteriormente.

No último experimento (fevereiro de 2006), a temperatura máxima oscilou de 26 ${ }^{\circ} \mathrm{C}$ (temperatura ótima) até $34^{\circ} \mathrm{C}$ e a mínima de $21^{\circ}$ a $30^{\circ} \mathrm{C}$ (Figura 5). Do $6^{\circ}$ ao $22^{\circ}$ dias praticamente não houve ocorrência de operários nos tubos de vidro, exceto nos tubos contendo folhas "in natura" $\left(19^{\circ} \mathrm{dia}\right)$ e raiz seca $\left(6^{\circ}\right.$ dia). Em todo o experimento 4 os tratamentos mais visitados foram o colmo e raiz "in natura".

O material da isca artificial de papelão ondulado apresentou-se de forma intermediária na escala de preferência. Apesar de em alguns resultados o papelão ter se igualado às estruturas morfológicas secas de $B$. brizantha, fica difícil concluir que o mesmo não foi atrativo. Deve-se atentar que o papelão é oriundo de madeira e Heterotermes tenuis é cupim que ataca madeira e talvez seja essa a razão do bom funcionamento do papelão como isca para essa espécie de praga no seu monitoramento. Portanto, para o levantamento de cupins em áreas de pastagens, a isca de papelão ondulado, normalmente utilizada para Heterotermes tenuis, provavelmente deve apresentar menor eficiência para $C$. cumulans. Os cupins de montículos (principalmente os do gênero Cornitermes), embora comumente encontrados em pastagens degradadas, ou em processo de degradação, não devem ser considerados como a causa principal da degradação, sendo a proliferação desses insetos vista como o resultado do manejo inadequado do solo e da planta, causadores do desequilíbrio ambiental (Dias-Filho, 2011). Todavia, no presente experimento, devido às maiores preferências por estruturas morfológicas "in natura" de B. brizantha, danos diretos podem ser provocados por C. cumulans às pastagens de gramíneas forrageiras cultivadas, pois há potencial efetivo para estes insetos forragearem tecidos "vivos" das plantas, como já constatado e discutido anteriormente.

Assim, não se pode descartar a importância do C. cumulans como inseto praga em gramíneas forrageiras no Brasil, pois dependendo das condições ecológicas do pasto a abundância desse agente biótico poderá contribuir no processo de degradação das pastagens, consumindo estruturas morfológicas "in natura" e debilitando ainda mais a longevidade produtiva dos pastos. 


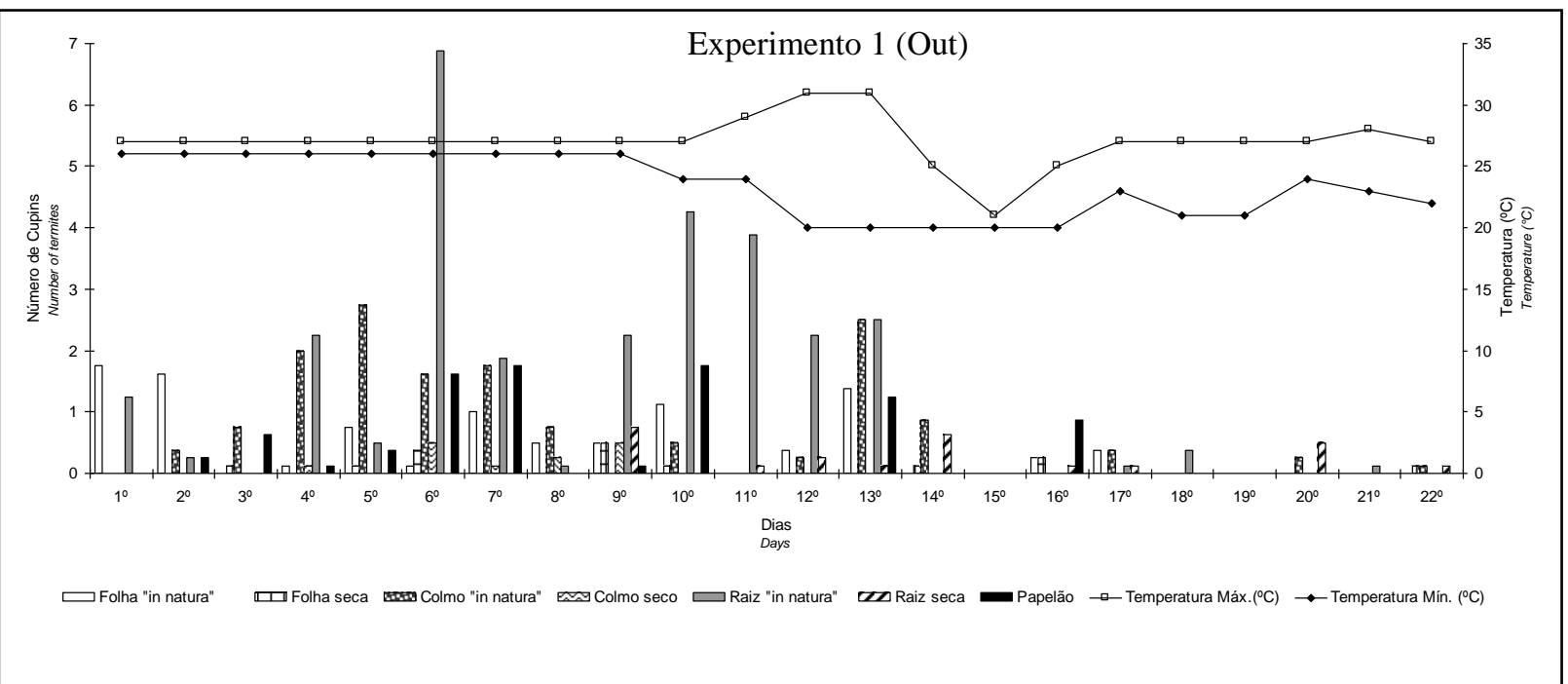

Figura 2. Temperaturas máxima e mínima diárias e média de visitações diárias por Cornitermes cumulans aos tratamentos no laboratório. Parauapebas-PA, 2005.

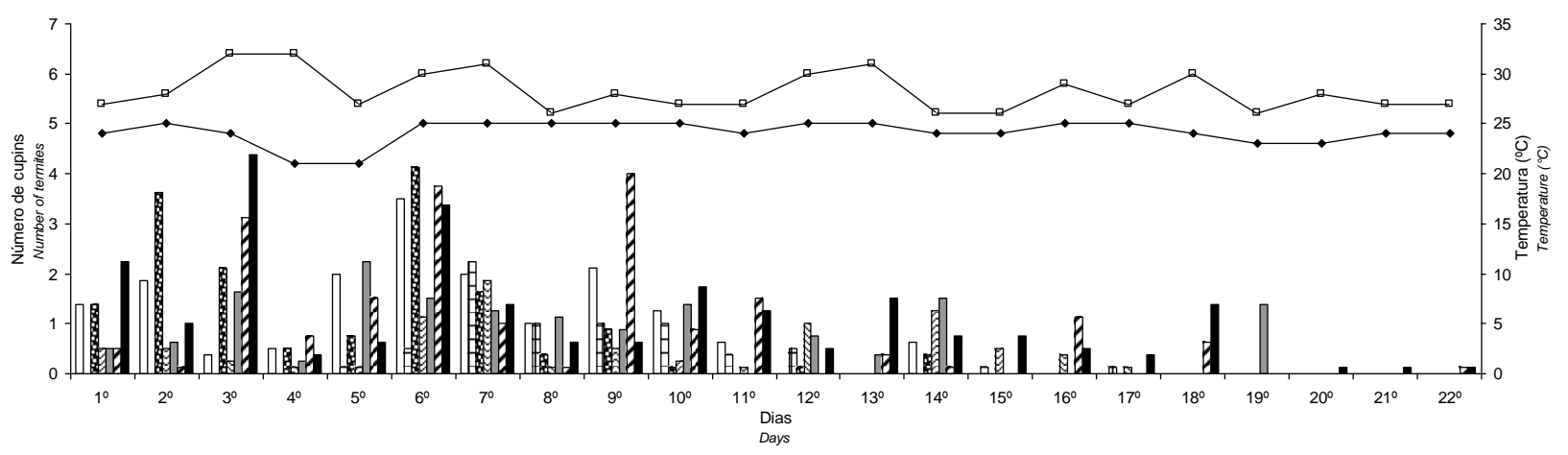

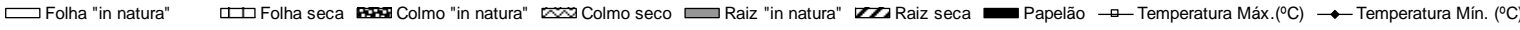

Figura 3. Temperaturas máxima e mínima diárias e média de visitações diárias por Cornitermes cumulans aos tratamentos no laboratório. Parauapebas-PA, 2005. 


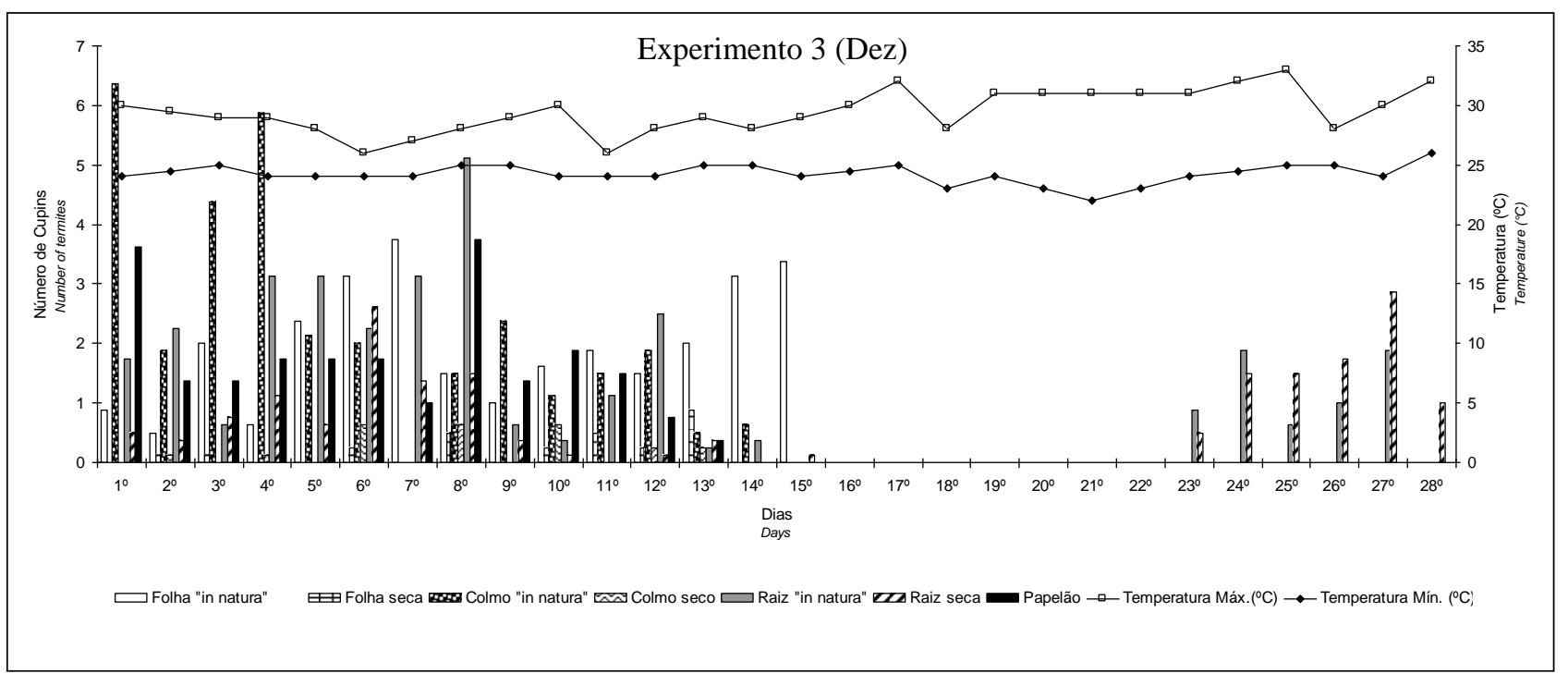

Figura 4. Temperaturas máxima e mínima diárias e média de visitações diárias por Cornitermes cumulans aos tratamentos no laboratório. Parauapebas-PA, 2005.

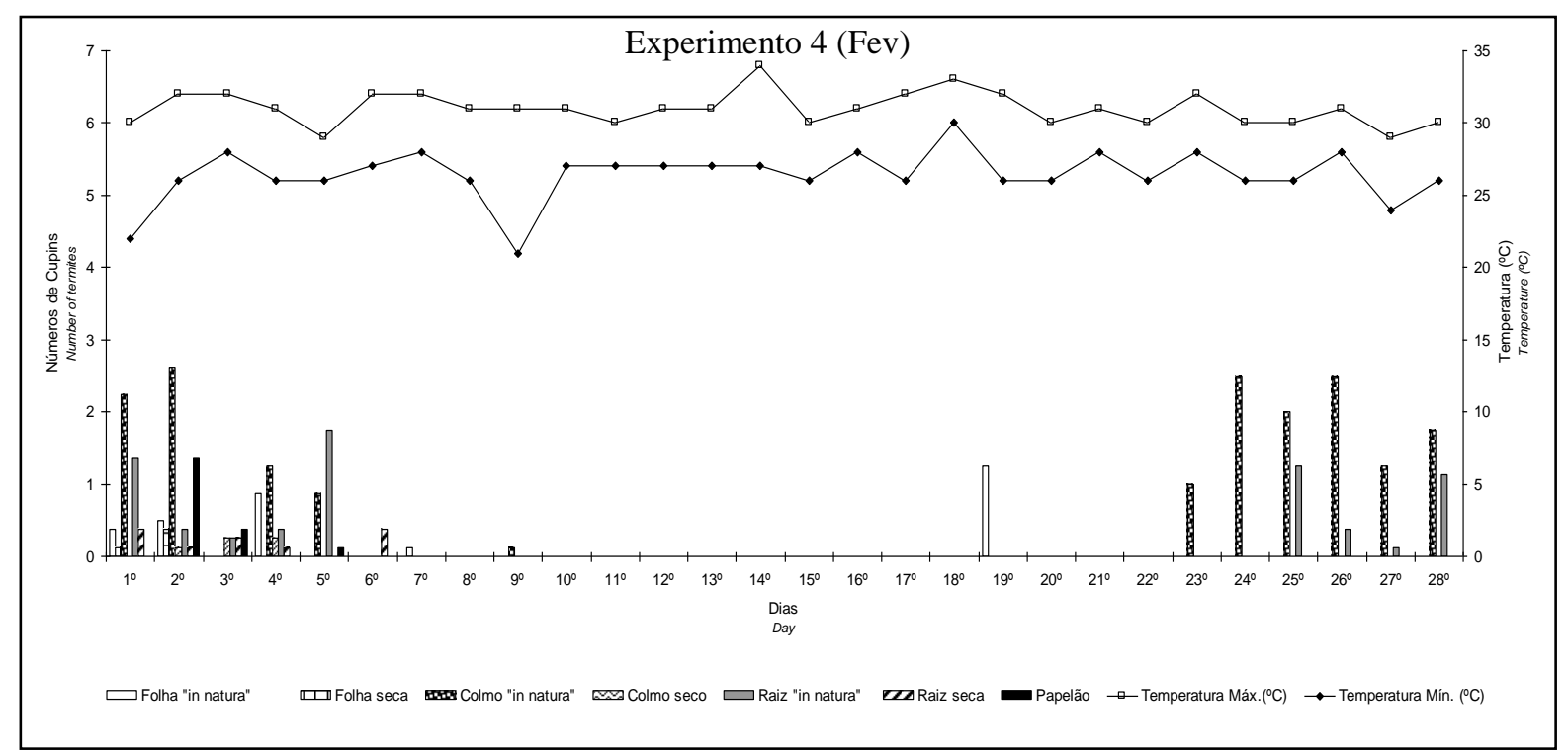

Figura 5. Temperaturas máxima e mínima diárias e média de visitações diárias por Cornitermes cumulans aos tratamentos no laboratório. Parauapebas-PA, 2006.

\section{CONCLUSÃO}

Os cupins-de-montículo, Cornitermes cumulans, podem consumir estruturas morfológicas "in natura" de Brachiaria brizantha (folha, colmo e raiz), constituindose nos materiais preferidos e visitados.

$\mathrm{O}$ papelão ondulado apresentou atração intermediária, sugerindo sua menor eficiência para utilização como isca no monitoramento de $C$. cumulans.

\section{AGRADECIMENTOS}

Ao IBAMA pela licença de pesquisa e acesso à Área de Proteção Ambiental - APA e a Associação dos Produtores da APA do 
Igarapé Gelado pela concessão das áreas de coleta e apoio logístico.

\section{REFERÊNCIAS BIBLIOGRÁFICAS}

ALMEIDA, J.E.M.; ALVES, S.B. Seleção de armadilhas para Heterotermes tenuis em condições de laboratório e campo. Anais da Sociedade Entomológica Brasileira, v. 24, n. 3, p. 619, 1995.

ALMEIDA, J.E.M. Avaliação de fungos entomopatogênicos visando ao controle do cupim subterrâneo Heterotermes tenuis (Hagen, 1858) (Isoptera: Rhinotermitidae). Piracicaba, 1994. 105p. Dissertação (Mestrado), Escola Superior de Agricultura "Luiz de Queiroz".

BANZATO, D.A.; KRONKA, S.N. 1989. Experimentação agrícola. FUNEP: Jaboticabal, 1989. 247p.

BECKER, G. Rearing of termites and testing methods used in the laboratory. In: KRISHNA, K.; WEESNER, F. (Ed.). Biology of Termites. London: Academic Press, 1969. p. 351-385.

BERTI FILHO, E. Cupins ou Térmitas. In: BERTI FILHO, E. (Ed.). Manual de pragas florestais. Piracicaba: IPEF-SIF, 1993. 56p.

DIAS-FILHO, M.B. Degradação de pastagens: processo, causas e estratégias de recuperação. 4.ed. Belém: Embrapa Amazônia Oriental, 2011. 213 p.

CANCELLO, E.M. Revisão de Cornitermes Wasmann (Isoptera: Termitidae, Nasutitermitinae). São Paulo, 1989. 136p. Tese (Doutorado) Instituto de Biociências.
CAMPO - CIA DE PROMOÇÃO AGRÍCOLA. Levantamento dos Recursos Naturais - APA do Gelado. Brasília, v.1. 1999. 306p.

COENZA, A.W.; CARVALHO, M.M. Controle de nível de dano do cupim de montículo em pastagens. Revista da Sociedade Brasileira de Zootecnia. v. 3, n. 1, p. 55-60,1974.

CZEPAK, C.; ARAÚJO, E.A.; FERNANDES, P.M. Ocorrência de espécies de cupins de montículo em pastagens no estado de Goiás. Pesquisa Agropecuária Tropical, v. 33, n. 1, p. 35-38, 2003.

EMPRESA BRASILEIRA DE PESQUISA AGROPECUÁRIA - EMBRAPA. Sistema Brasileiro de Classificação de Solos. 2 ed. Rio de Janeiro: Embrapa Solos, 2006.

EMPRESA BRASILEIRA DE PESQUISA AGROPECUÁRIA - EMBRAPA. Cupim de Montículo em Pastagens. Campo Grande: Centro Nacional de Pesquisas de Gado de Corte, 1996.

FERNANDES, P.M.; ALVES, S.B. Preferência de Cornitermes cumulans (Kollar, 1832) (Isoptera: Termitidae) às plantas cultivadas, em laboratório. Anais da Sociedade Entomológica do Brasil, v. 21, n. 2, p. 125-132, 1992.

INSTITUTO BRASILEIRO DE GEOGRAFIA E ESTATÍSTICA (IBGE). Manual técnico de uso da Terra. Rio de Janeiro: IBGE, 2006.

LEITÃO-LIMA, P.S. Cornitermes cumulans KOLLAR, 1832 (Isoptera: Termitidae): preferência a diferentes substratos e avaliação de danos em plantas de eucalipto. Botucatu, 2005. 67p. Tese (Doutorado) - Faculdade 
Ciências Agronômicas, Universidade Estadual Paulista "Júlio de Mesquita Filho".

MACEDO, N. Atualização no controle de cupins subterrâneos em cana-de-açúcar. In: BERTI FILHO, E., FONTES, L.R. (Ed). Aspectos atuais da biologia e controle de cupins. Piracicaba: FEALQ, 1995. p.121-126.

NOGUEIRA, S.B. Os cupins. Viçosa: Editora UFV, 1981, 27p.

SILVEIRA NETO, S. Controle de insetos e outras pragas das pastagens. In: SIMPÓSIO SOBRE O MANEJO DE PASTAGENS, 3. (Ed.). Piracicaba: Fundação Cargill, 1976. p.137-190.

VALÉRIO, J.R. Restrições biológicas a produção animal a pasto: In: REUNIÃO ANUAL DA SOCIEDADE BRASILEIRA DE ZOOTECNIA, 38. (Ed.). Piracicaba: Sociedade Brasileira de Zootecnia, 2001. CD-ROM (Palestra)

VALÉRIO, J.R.; OLIVEIRA, A.R; KOLLER, W.W.; MARTIN, P.B.; NILAKHE, S.S.; CONSENZA, G.W.; NAVES, M.A.; GOMES, R.F.C.; MORAES, E.; SEMPREBOM, D.; MRAES, P.B. Cigarrinhas das pastagens: espécies e níveis populacionais no Estado do Mato Grosso do Sul e sugestões para o seu controle. Campo Grande: EMPAER, 1982. 20p.

VALÉRIO, J.R; SANTOS, A. V.; SOUZA, A. P.; MACIEL, A.M.; OLIVEIRA, M.C.M. Controle químico e mecânico de cupins de montículo (Isoptera: Termitidae) em pastagens. In: Anais da Sociedade Entomológica Brasileira, v. 27, n. 1, p. 125-131, 1998.
VALÉRIO, J.R. Ocorrência, danos e controle de cupins de montículo em pastagens. In: REUNIÃO SULBRASILEIRA DE INSETOS DO SOLO, 5. (Ed.). Dourados: EmbrapaCPAO, 1995. p. 33-36. 